This item was submitted to Loughborough's Research Repository by the author.

Items in Figshare are protected by copyright, with all rights reserved, unless otherwise indicated.

\title{
Accuracy of energy yield prediction of photovoltaic modules
}

\section{PLEASE CITE THE PUBLISHED VERSION}

http://dx.doi.org/10.1143/JJAP.51.10NF01

\section{PUBLISHER}

(C) The Japan Society of Applied Physics

\section{VERSION}

AM (Accepted Manuscript)

\section{LICENCE}

CC BY-NC-ND 4.0

\section{REPOSITORY RECORD}

Roy, Jyotirmoy, Thomas R. Betts, and Ralph Gottschalg. 2019. "Accuracy of Energy Yield Prediction of Photovoltaic Modules”. figshare. https://hdl.handle.net/2134/13035. 
This item was submitted to Loughborough's Institutional Repository (https://dspace.lboro.ac.uk/) by the author and is made available under the following Creative Commons Licence conditions.

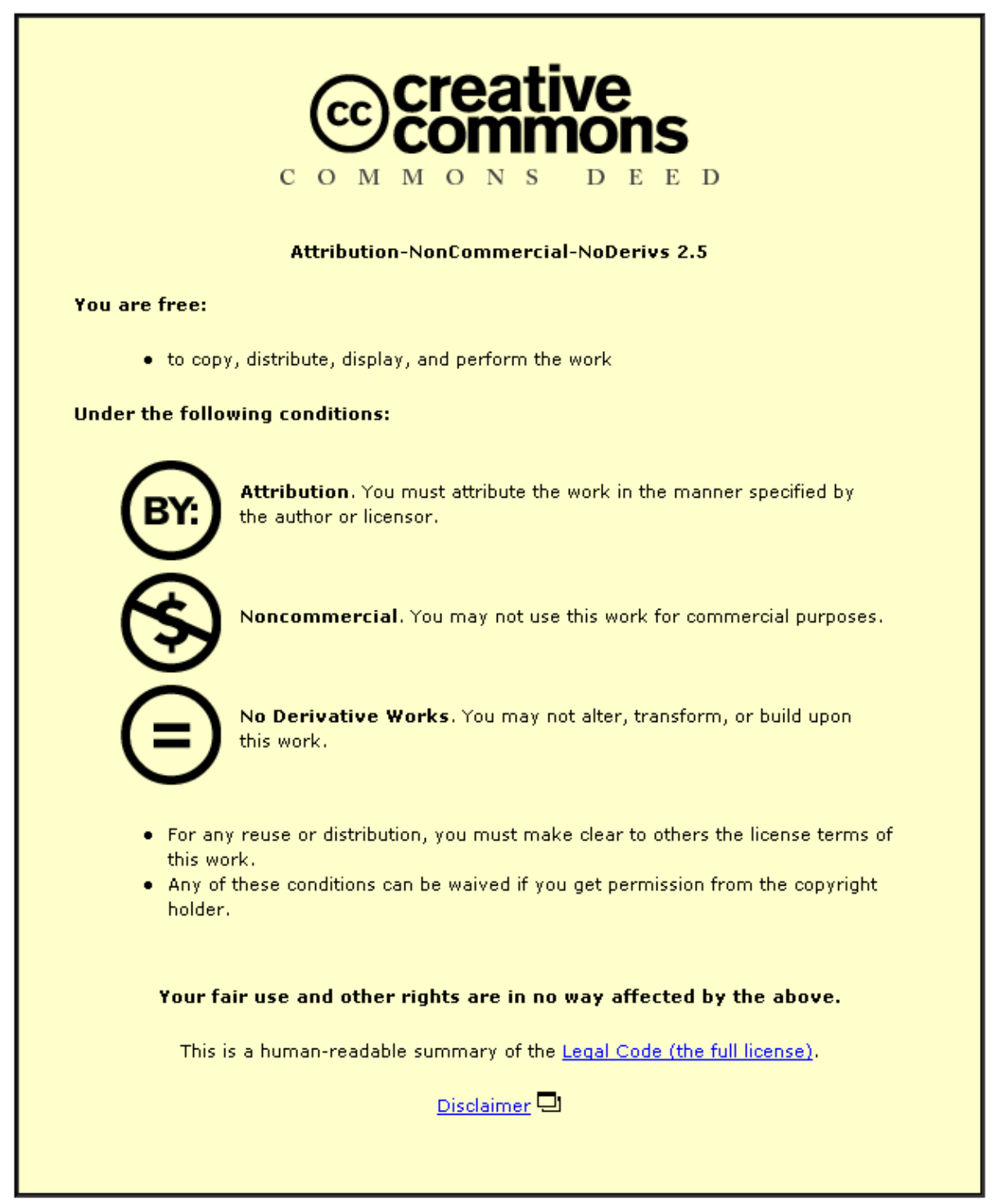

For the full text of this licence, please go to: http://creativecommons.org/licenses/by-nc-nd/2.5/ 


\title{
Accuracy of Energy Yield Prediction of Photovoltaic Modules
}

\author{
Jyotirmoy Roy*, Thomas Richard Betts and Ralph Gottschalg \\ Centre for Renewable Energy Systems Technology (CREST), School of Electronic \\ Electrical and Systems Engineering, \\ Loughborough University, Loughborough, LE11 3TU, UK \\ *E-mail address: J.Roy2@lboro.ac.uk
}

The uncertainty analysis of irradiance and temperature measurements in relation to the energy yield prediction of the photovoltaic (PV) modules are presented. A Monte Carlo simulation approach is demonstrated separately to propagate the monthly and annual measurement uncertainties of irradiance and temperature to annual energy yield prediction uncertainty for two commercially available PV modules. The annual irradiation uncertainty as measured with a thermopile pyranometer is calculated as $\pm 1.56 \%$. Uncertainty of the annual average of ambient temperature measurement is calculated as $\pm 0.08^{\mathrm{O}} \mathrm{C}$. Finally, the uncertainty in the energy yield estimation of the PV devices is determined as $2.8 \%$ and $15.5 \%$ for crystalline silicon (c-Si) and copper indium gallium (di)selenide (CIGS) modules, respectively.

KEYWORDS: Irradiance uncertainty, temperature uncertainty, energy yield prediction uncertainty

\section{Introduction}

In this article the uncertainty analysis of a photovoltaic (PV) module energy yield prediction procedure is studied. Uncertainties in the yield prediction come both from measurements and modelling involved in the prediction procedure. Estimation of the energy yield of PV module requires two sets of measured input data [1-5]:

- The PV module characterisation data, i.e., $\mathrm{P}_{\max }$ at wide range of irradiance and temperature (Fig. 1).

- The site specific environmental data, i.e., irradiance, temperature, spectral irradiance, etc.

Then additional modelling steps involved in the energy yield prediction method. The modelling comprises: 
- the translation of global horizontal irradiance into irradiance at plane of array of PV module [6],

- the estimation of module temperature [6],

- spectral and angular corrections [7,8] and

- $\quad$ estimation of maximum power of the PV module over the time period [6, 9].

Each of the above measured and modelling components contributes to the uncertainty in the final energy yield estimation. This paper concentrates on the contributions from irradiance and temperature measurements.

The uncertainty contributions can be classified into statistical and systematic components for a given parameter. Systematic uncertainty is a fixed error of an equipment but the statistical error is varied with the measurements. Guide to the expression of uncertainty in measurement (GUM) [1011] explains the procedure to estimate the statistical and systematic uncertainty. But the GUM uncertainty framework does not explicitly determine a probability distribution function for the output quantity [13].

As an alternative solution, a framework for the measurement uncertainty analysis based on Monte Carlo simulation is established and illustrated in this article, where a specified number of values of the same measurement is generated randomly [14]. The advantage with Monte Carlo method is, it can improve the uncertainty associated with the estimate of output quantity even for non-linear models [13]. The Monte Carlo simulation is then applied to analyse the uncertainty of irradiance and temperature measurement.

The magnitude of uncertainty over the range of irradiance and temperature measurement is then revealed. This gives an indication of the level of accuracy at different signal strength of irradiance and temperature measurements - which ultimately indicates the level of accuracy in the energy yield estimation in different location. Finally, this uncertainty model is applied to the international standard of energy rating model (IEC 61853) [15 - 17].

Evaluating the uncertainties of the input measured values, the IEC 61853 energy yield prediction method is validated against real measurements of annual energy generation of two different PV modules at Loughborough, UK. 


\section{Energy Yield Prediction Method}

The IEC 61853 standard energy rating method is used as a yield prediction method [7]. IEC 61853 is divided into three different parts. Part 1 [15] indicates the requirement for evaluating PV module performance in terms of power rating over a wide range of irradiance and module temperature. This gives a full set of characterization data at different irradiance and module temperature in a matrix form. Part 2 [16] explains the measurement and analytical approach on the effects of angle of incidence (AOI), spectral response and the module operating temperature. Part 3 [17] consists of the calculation of energy rating procedures based on measured and modelled values of parts 1 and 2 .

The meteorological data used is taken from the CREST outdoor measurement system. A matrix of maximum power $\left(\mathrm{P}_{\max }\right)$ of the module over a wide range of irradiance and temperature is measured indoors in a controlled environment at the Austrian Institute of Technology, Vienna (Fig. 1).

Power matrices of two module technologies, c-Si and CIGS, are used in this study. The $\mathrm{P}_{\max }$ at target irradiances and temperatures are estimated by a linear regression method at each timestamp of the annual dataset. The integration of the estimated $\mathrm{P}_{\max }$ at all timestamps gives the annual energy yield estimation of the module. For the validation of this analysis, identical modules are also measured at the CREST outdoor system to log their annual energy output.

\section{Monte Carlo Approach}

A Monte Carlo technique is used in this study for uncertainty propagation analysis. This is done by performing random sampling from the probability distribution of each input parameter and evaluating the model output several times using a different set of randomly selected values from the probability density functions.

A flow chart of a Monte Carlo simulation procedure is shown in Fig. 2, where the measured value of each uncertainty parameters (i.e. irradiance and temperature) is taken as the input into the model. Monte Carlo method is a mathematical simulation, is performed with a specified uncertainty scale factor against the measured values of the input parameters in order to generate random number of specified iteration. A system model also needed to be selected for random number generation. A normal distribution is used in this study for the probability distribution of each input parameters. Normal distribution defines the mean and a standard deviation to describe the random variation 
about the mean. Comparing the estimated mean and standard deviation of the probability distribution against a true value of the same parameter gives the uncertainty of the test parameter.

All irradiance and temperature measured data are taken from the CREST outdoor monitoring system (COMS) at Loughborough University, Loughborough, UK, where irradiance sensors are installed in the horizontal and inclined plane of module installation and temperature sensors are installed at the back of each module. Ten second timestamps of the annual data from October 2009 to November 2010 is used for this analysis.

\section{Measurement Uncertainty of Environmental Data}

\subsection{Irradiance measurement uncertainty}

Irradiance is the primary input parameter that largely influences the power output of a PV module. There are different irradiance measurement sensors available (Kipp \& Zonen CM22, CMP 11, etc.) offering different levels of measurement accuracy. The Kipp \& Zonen CM 11 pyranometer [17], an older but commonly used sensor, is utilised in the analysis as a case study. Previous irradiance uncertainty measurement studies only used the given uncertainty values in the equipment manufacturers manual [19-27]. A robust model is established that can analyse the irradiance measurement uncertainty and is applicable to any location. The irradiance uncertainty components of the CM 11 sensor are categorised into two groups:

- uncertainties that change annually (Table 1),

- uncertainties that change at each timestamp of measurement (Table 2).

Additionally, there are three other uncertainty sources described in the CM 11 manual. These are variable depending on the signal strength of irradiance i.e. non-linearity of irradiance (0-1000 $\mathrm{W} / \mathrm{m}^{2}$ ), temperature i.e. temperature dependence of sensitivity (-20 to $50{ }^{\circ} \mathrm{C}$ ) and zenith angle, i.e., directional zenith angle error $\left(0-80^{\circ}\right)$. The level of uncertainty of non-linearity of irradiance sensitivity, temperature sensitivity and directional error is extracted at each timestamp.

\subsubsection{Non-linearity error}

The sensitivity variation with irradiance for the given CM 11 sensor is included with a linear model to estimate the non-linearity error against variable irradiance at every timestamp of the measurement (Fig. 3). 


\subsubsection{Temperature dependence of sensitivity}

The temperature dependence of the sensitivity is specific to an individual sensor. For the CM 11 the uncertainty lies somewhere within the upper boundary and lower boundary about a reference baseline (see Fig. 4).

A fourth order polynomial representation is applied to estimate the baseline reference (Fig. 4) at any target ambient temperature. Then a Monte Carlo method is utilised for the probability of the distribution of the error based on the standard deviation within the upper and lower boundaries of the sensitivity curve in Fig. 4.

\subsubsection{The directional error}

This is the summation of the azimuth and zenith error. Fig. 5 shows the maximum relative zenith error in any azimuth direction for the CM 11 sensor.

A linear interpolation method is applied to estimate the baseline reference at any targeted zenith angle and a fourth order polynomial model is applied to estimate the positive and negative error at different zenith angles. Then a Monte Carlo method is utilised for the probability of distribution of the error based on the standard deviation within upper and lower boundaries of the zenith angle sensitivity curve of Fig. 5.

Based on the above uncertainty components and their scale factors, the annual irradiance measurement overall uncertainty is determined using a Monte Carlo method. Measured global horizontal irradiance $\left(\mathrm{G}_{\mathrm{hor}}\right)$ data are assumed as true values in this analysis. The same irradiance, i.e., $\mathrm{G}_{\text {hor }}$ is used as the input basis for the Monte Carlo simulation.

The uncertainty of the $G_{\text {hor }}$ measurement at each timestamp is then summed for the whole year in order to evaluate the uncertainty of annual irradiation. Five thousand draws have been chosen to build the final probability distribution of the annual irradiation; the result is shown in Fig. 6, which represents a Gaussian distribution.

Using all the above listed uncertainty components, the uncertainty of annual irradiation from measurements with the CM 11 sensor is calculated as $\pm 1.56 \%$. Monthly uncertainty ranges from $\pm 2 \%$ to $\pm 6.2 \%$ depending on the irradiation in different months of the year (Fig. 7). These values are within the agreement that have been reported elsewhere [28]. 


\subsection{Temperature measurement uncertainty}

Temperature is the second most influential parameter after irradiance that determines the power output of a PV module. So, accurate temperature measurement is also critical in order to estimate the energy yield of different PV technologies. As with irradiance, there are a variety of temperature sensors available with different levels of measurement accuracy. This study takes a Vaisala HMP45C P1000 sensor [29] as a case study, as it is in use for ambient temperature measurements in the CREST outdoor monitoring system. The results are applicable to sensors monitoring module temperatures also.

The measurement uncertainty of HMP45C P1000 is taken from manufacturer datasheet (Fig. 8) and uses the Monte Carlo method for annual and monthly temperature measurement uncertainty.

Measured ambient temperature $\left(\mathrm{T}_{\mathrm{amb}}\right)$ data are assumed as the true values in this analysis. The uncertainty scale factor of the chosen sensor has been estimated using linear interpolation based on the data shown in Fig. 8 and Monte Carlo simulation is used to draw random uncertainty values and estimate annual and monthly average ambient temperature measurement uncertainty. Again, five thousand samples have been chosen to generate random numbers within the given range of uncertainty of $\mathrm{T}_{\mathrm{amb}}$ at each time stamp for the whole year and the annual sum is estimated for each sample set.

The uncertainty of annual average ambient temperature measurement is calculated as $\pm 0.08^{\mathrm{O}} \mathrm{C}$ and the uncertainty of monthly average of ambient temperature is illustrated in Fig. 9, which is within agreements that have been reported elsewhere [30 - 31].

\section{Energy Yield Estimation Uncertainty}

Based on the above measurement uncertainties of irradiance and temperature, the uncertainty of annual energy yield for c-Si and CIGS PV modules were determined through propagation and are listed in Table 3. The monthly energy yield estimation uncertainties of the c-Si module, as an example, are shown in Fig. 10.

Higher uncertainties in December to February occur due to not only the higher input uncertainties from irradiance and temperature measurements but quite significantly due to the reason that the 
linear regression of $\mathrm{P}_{\max }$ does not match well at lower irradiance level. The linear regression method is suggested in the IEC 51853 to estimate the $\mathrm{P}_{\max }$ at target irradiances and temperatures.

\section{Conclusions}

This paper established a robust analytical procedure for propagating the measurement uncertainties of irradiance and temperature for energy yield prediction. A Monte Carlo simulation approach is applied which should be applicable to any location at different weather profile. For the evaluation of this procedure, the method has been validated at Loughborough, UK. The irradiance sensor used as a reference is CM 11 pyranometer which gives $\pm 1.56 \%$ annual irradiation uncertainty in the UK climate. The temperature sensor studied is a HMP45C Pt1000 sensor which resulted $\pm 0.08^{\mathrm{O}} \mathrm{C}$ annual average temperature uncertainty.

The estimated uncertainties of the annual energy yield prediction of c-Si and CIGS PV modules are 2.8 and 15.5\%, respectively. These values will vary depending on the annual irradiance and temperature profile of a specific location.

This study estimated the $\mathrm{P}_{\max }$ at target irradiance and temperature points by linear regression method at each timestamp of the total time period and also did not include the spectral correction factor. Two possible reasons for the high uncertainties achieved in this study are because of the non-linear response of actual power generation of the PV modules over the range of irradiance and also the spectral sensitivity and seasonal material changes. The achievable uncertainties for both modules will most likely be improved by employing spectral irradiance correction to the AM 1.5 standard spectrum, particularly for the thin film module. It should also be noted that the modelling uncertainties noted in the introduction also influence the energy yield uncertainty.

\section{REFERENCES}

[1] S. R. Williams, T. R.Betts, R. Gottschalg, D. G. Infield, H. de Moor, N. van der Borg, A. R. Burgers, G. Friesen, D. Chianese, A. Guerin de Montgareuil, T. Zdanowicz, D. Stellbogen, and W. Herrmann: Proc. 34 ${ }^{\text {th }}$ IEEE, (2006).

[2] R. P. Kenny, G. Friesen, D. Chianese, A. Bernasconi, and E. D. Dunlop: Prog. in Photovoltaics, Vol. 3, (2002).

[3] K. Bucher, G. Kleiss, and D. Batzner: Proc. 26 ${ }^{\text {th }}$ IEEE, (1997).

[4] G. Friesen, D. Chianese, I. Pola, A. Realini, and A. Bernasconi: Proc. EUPVSEC, (2007). 
[5] D. L. King: Proc. NREL/SNL Photovoltaics Program Review Meet, New York, (1997).

[6] J. Roy, T.R. Betts, R. Gottschalg: Proc. of the PVSAT-UK, 2011.

[7] J. Roy, T. R. Betts, R. Gottschalg, S. Mau, S. Zamini, R. P. Kenny, H. Müllejans, G. Friesen, S. Dittmann, H. G. Beyer, and A. Jagomägi, Proc. EUPVSEC, Valencia, (2008).

[8] R. Gottschalg, T. R. Betts, D. G. Infield, and M J Kearney: Meas. Sci. Technol. (2004).

[9] G. Friesen, R. Gottschalg, H. G. Beyer, S. Williams, A. Guerin de Montgareuil, N. van der Borg, W. G. J. H. M. van Sark, T. Huld, B. Müller, A.C. de Keizer, and Y. Niu: Proc. EUPVSEC, (2007).

[10] PD 6461-3: (1995).

[11] PD 6461-4: (2004).

[12] R. B. Abernethy and B. Ringhiser: Proc. AIAA/SAE/ASME/ASME 21st Joint Propulsion Conf., (1985).

[13] JCGM 101 (2008).

[14] J. Roy, T. R. Betts, and R. Gottschalg: Proc. PVSEC - 21, (2011).

[15] IEC 61853-1 Draft H Standard, (2007).

[16] IEC 61853-2 Draft E Standard, (2007).

[17] IEC 61853-3 Draft C Standard, (2007).

[18] Kipp \& Zonen CM11 Instrument Manual, (2008).

[19] M. B. Strobel, T. R. Betts, G. Friesen, H. G. Beyer, and R. Gottschalg: Sol. Energy Mater. Sol. Cells, (2009).

[20] K. Whitfield, and C. R. Osterwald: Prog. Photovoltaics, (2001).

[21] D. R. Myers: Solar Energy 1989.

[22] G. H. Atmaram: Conf. Rec.IEEE 4th World Conf. 2006.

[23] K. Emery: Tech. Rep-NREL/TP-520-45299, 2009.

[24] K. A. Emery, and C. R. Osterwald: Proc. $19^{\text {th }}$ IEEE Photovoltaic, 1987.

[25] H. Müllejans, W. Zaaiman, and R Galleano: Meas. Sci.Tech. 2009.

[26] C. Leboeuf, and H. A. Ossenbrink: Proc. 22nd IEEE, 1991.

[27] R. Gottschalg: Proc.35 ${ }^{\text {th }}$ IEEE, 2010.

[28] M. G. Kratzenberg, H. G. Beyer, S. Colle, and A. Albertazzi: Proc. ASME, 2006.

[29] HMP45C, instrument manual, (2008).

[30] R. E. Bentley: National Measurement Laboratory, 2001.

[31] K. G. Hubbard, and X Lin: Structures and Environnent Division of ASAE, 2003. 


\section{Table}

Table 1: Uncertainties that change annually.

\begin{tabular}{cc}
\hline Uncertainty cause & Uncertainty $\left(\mathrm{W} / \mathrm{m}^{2}\right)$ \\
\hline Calibration & \pm 3.4 \\
Annual drift & \pm 0.00288
\end{tabular}

Table 2: Uncertainties that change at each timestamp of measurement.

\begin{tabular}{ll}
\hline Uncertainty cause & Uncertainty \\
\hline Zero-offset due to temperature change $(5 \mathrm{~K} / \mathrm{h})$ & $\pm 2 \mathrm{~W} / \mathrm{m}^{2}$ \\
Zero-offset due to thermal radiation $\quad\left(200 \mathrm{~W} / \mathrm{m}^{2}\right)$ & $\pm 7 \mathrm{~W} / \mathrm{m}^{2}$ \\
Tilt error (beam $\left.1000 \mathrm{~W} / \mathrm{m}^{2}\right)$ & $\pm 0.25 \%$ \\
Spectral sensitivity & $\pm 2 \%$
\end{tabular}

Table 3: Uncertainty of annual energy yield of c-Si and CIGS PV module.

\begin{tabular}{llll}
\hline Module & $\mathrm{P}_{\max }(\mathrm{Wp})$ & Uncertainty (\%) & Distribution \\
\hline C-Si & 10 & 2.78 & Normal \\
CIGS & 5 & 15.45 & Normal
\end{tabular}

\section{Figures}

Fig. 1: $\mathrm{P}_{\max }$ matrix of IEC 61853 Energy rating method as a function of irradiance and temperature.

\begin{tabular}{|c|c|c|c|c|}
\hline & Tempera & $\left({ }^{\circ} \mathrm{C}\right)$ & & \\
\hline Irradiance $\left(\mathrm{W} / \mathrm{m}^{2}\right)$ & 15 & 25 & 50 & 75 \\
\hline 1100 & $\bullet$ & $\bullet$ & $\bullet$ & $\bullet$ \\
\hline 1000 & $\bullet$ & $\bullet$ & $\bullet$ & $\bullet$ \\
\hline 800 & $\bullet$ & $\bullet$ & $\bullet$ & $\bullet$ \\
\hline 600 & $\bullet$ & $\bullet$ & $\bullet$ & $\bullet$ \\
\hline 400 & $\bullet$ & $\bullet$ & $\bullet$ & $\bullet$ \\
\hline 200 & $\bullet$ & $\bullet$ & $\bullet$ & $\bullet$ \\
\hline 100 & $\bullet$ & $\bullet$ & $\bullet$ & $\bullet$ \\
\hline
\end{tabular}


Fig. 2: Framework of Monte Carlo simulation approach.

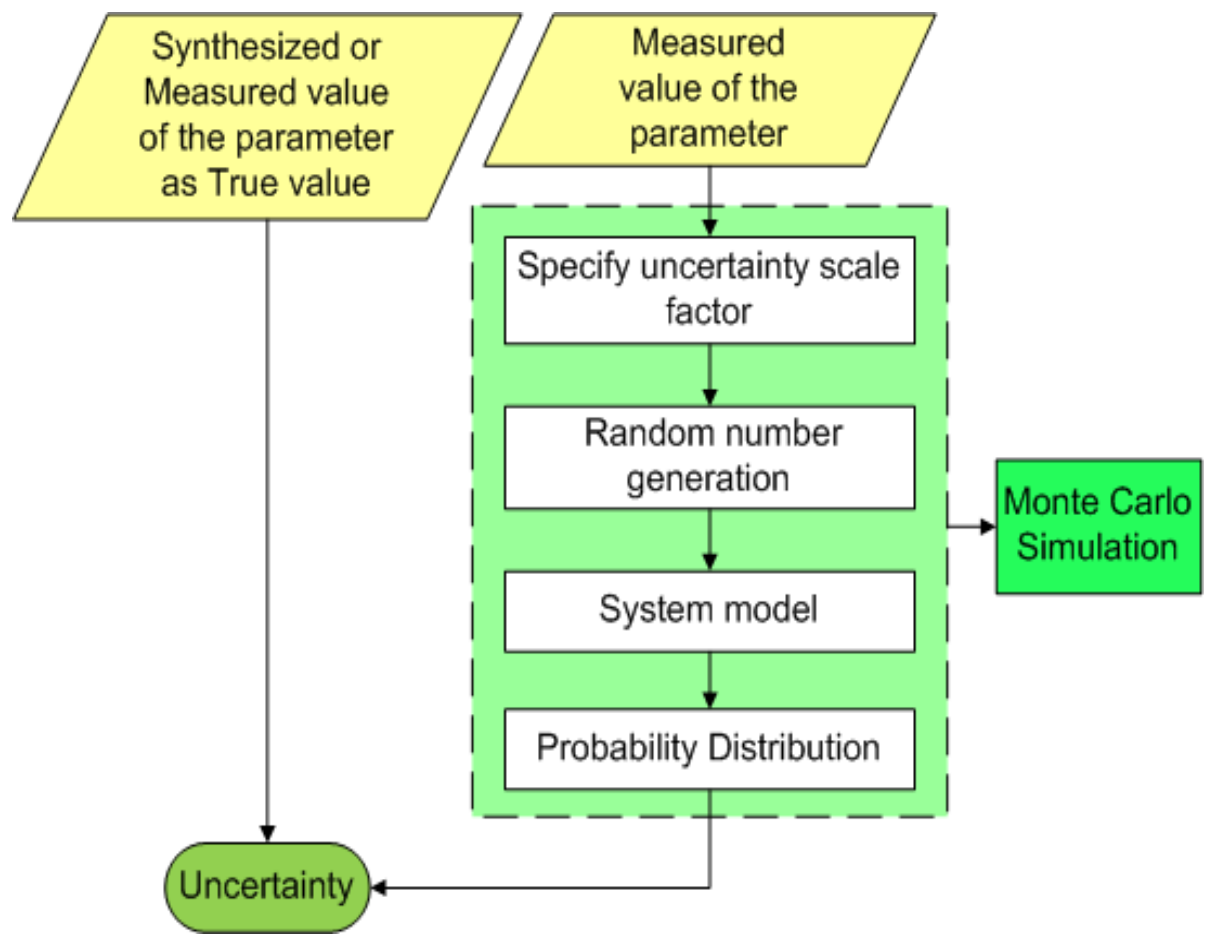

Fig. 3: Non-linearity error of Kipp \& Zonen CM11 pyranometer.

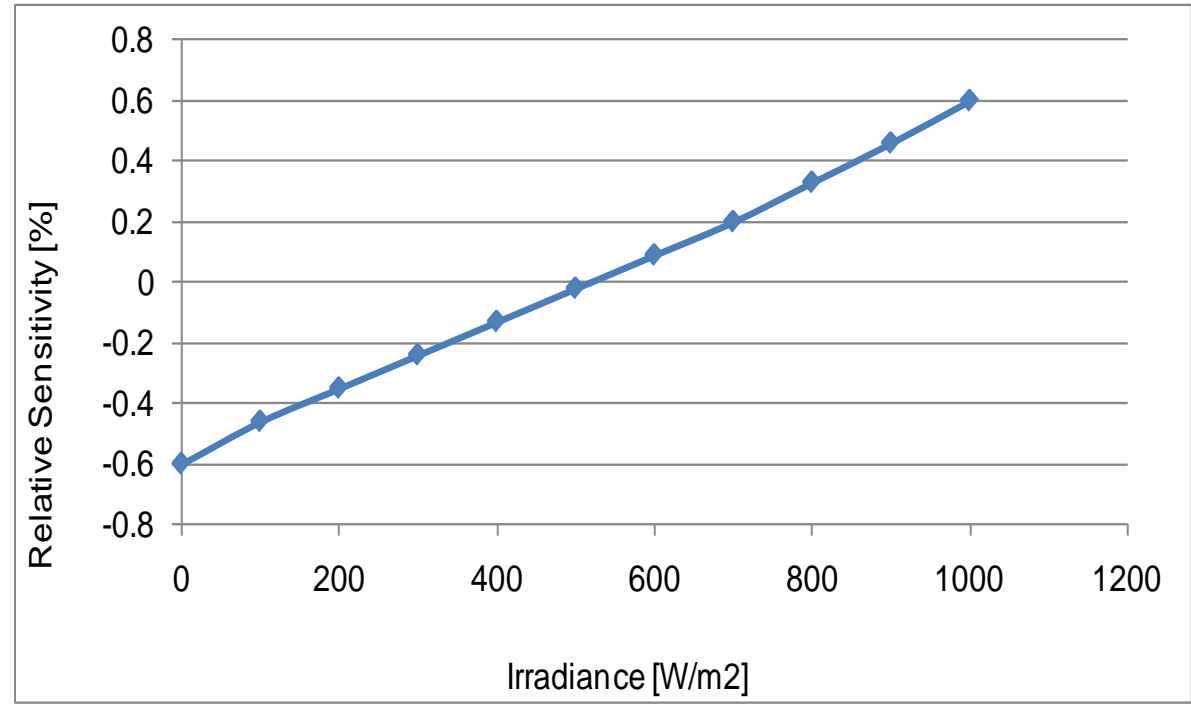


Fig. 4: Relative variation of sensitivity with instrument temperature of a Kipp \& Zonen CM11 pyranometer.

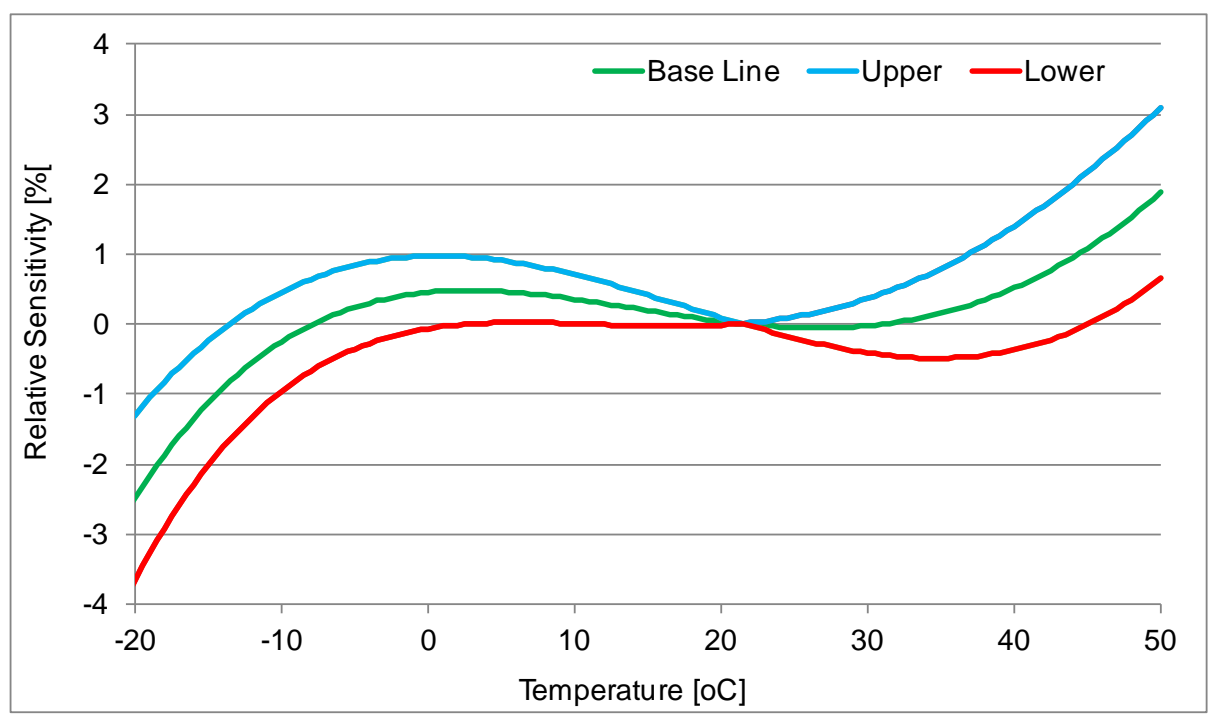

Fig. 5: Directional error.

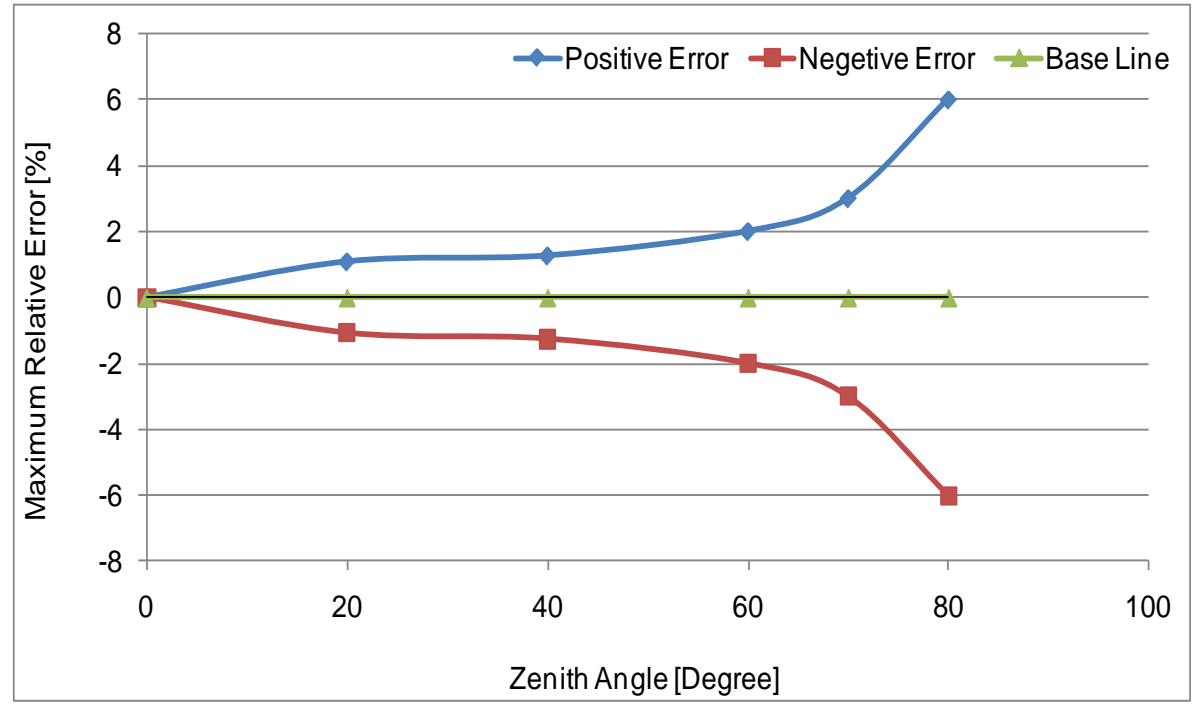

Fig. 6: Probability distribution of annual global horizontal irradiation measurement uncertainty by CM 11. 


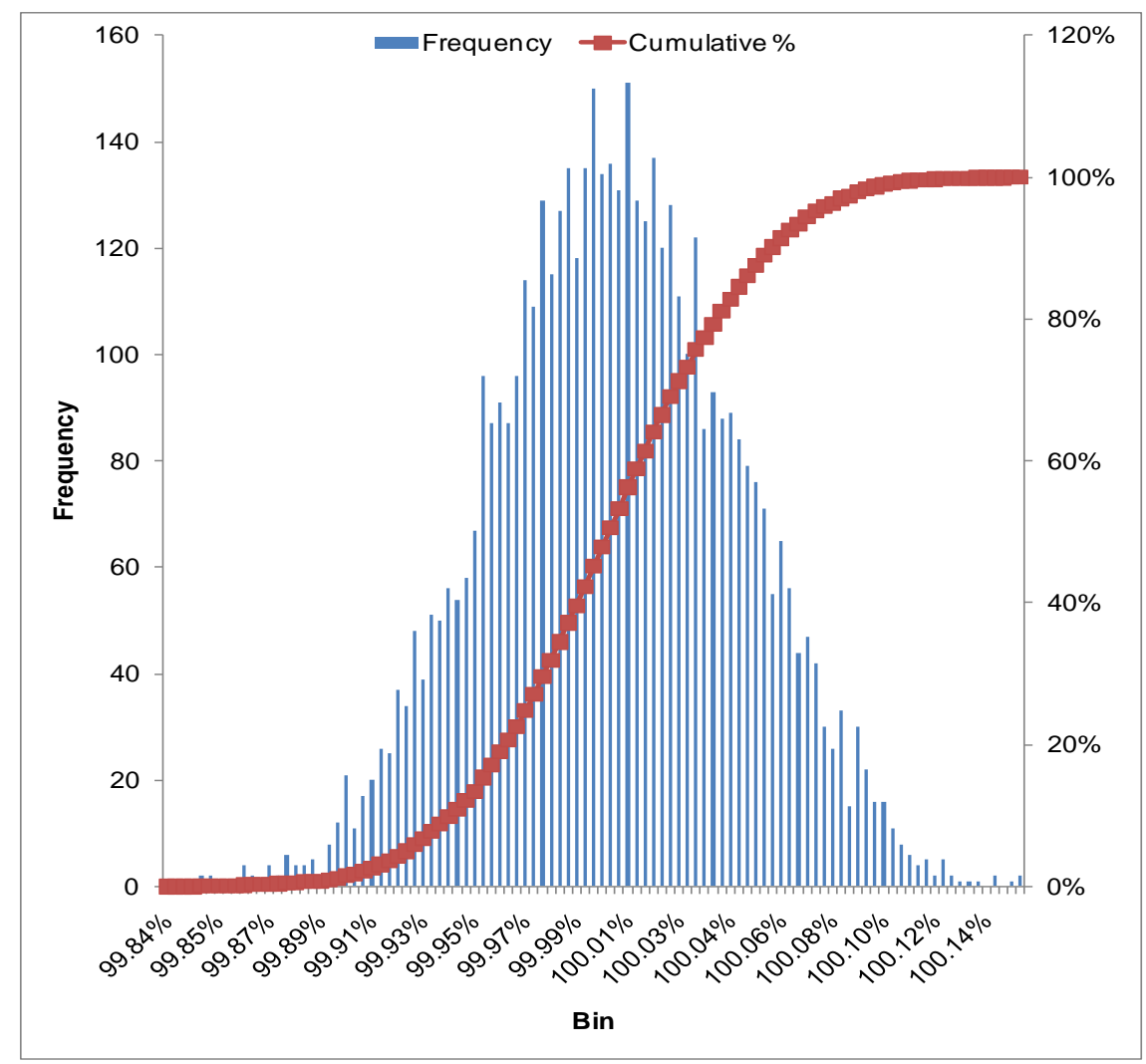

Fig. 7: Monthly irradiation $\left(\mathrm{kW} \mathrm{h} / \mathrm{m}^{2}\right)$ and measurement uncertainty in the UK climate.

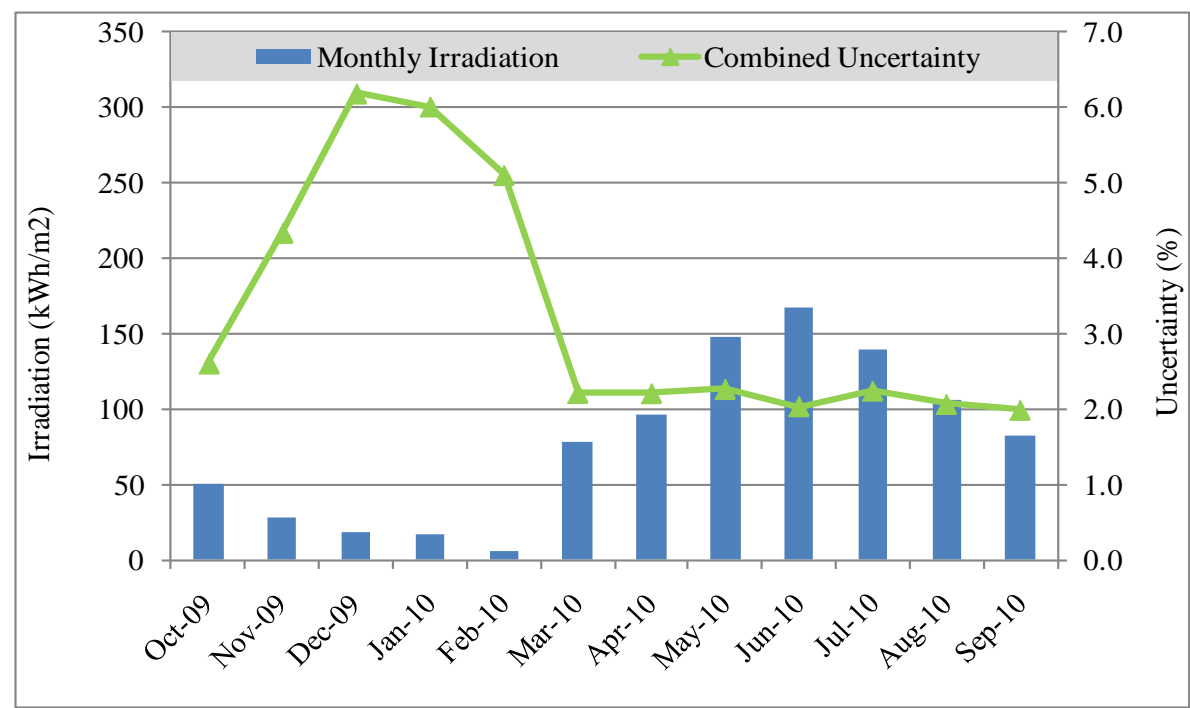

Fig. 8: Measurement uncertainty of the HMP45C P1000 sensor. 


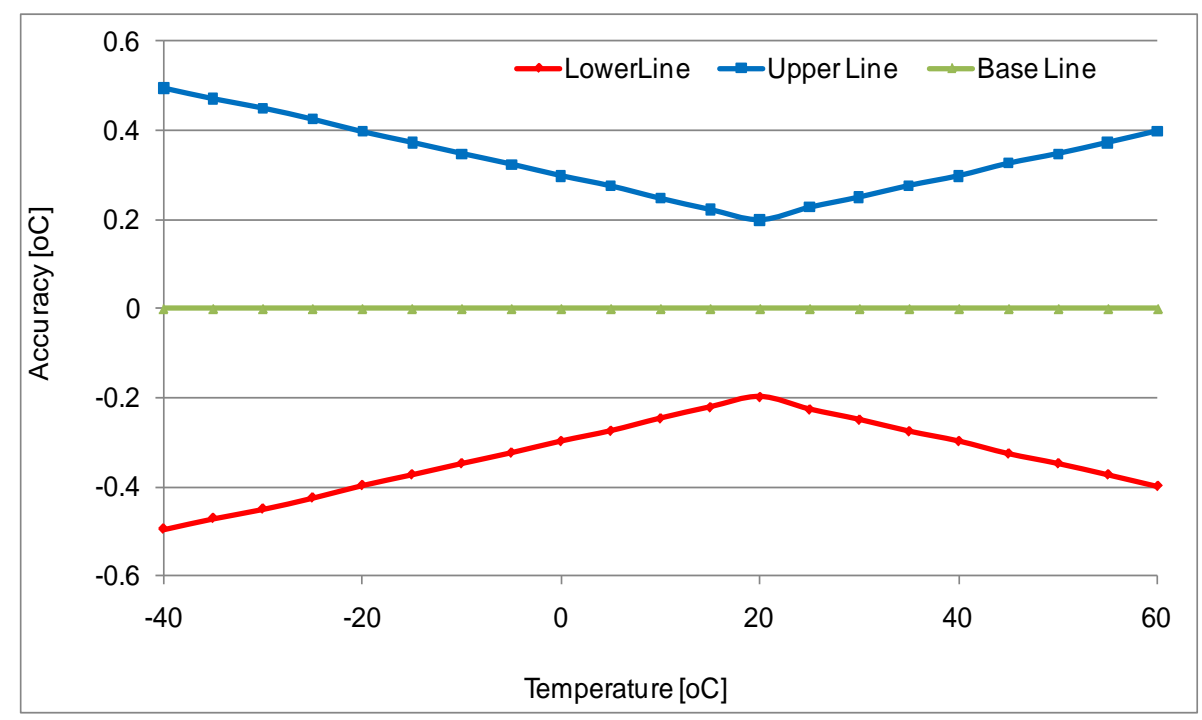

Fig. 9: Monthly average ambient temperature and their uncertainties in UK climate.

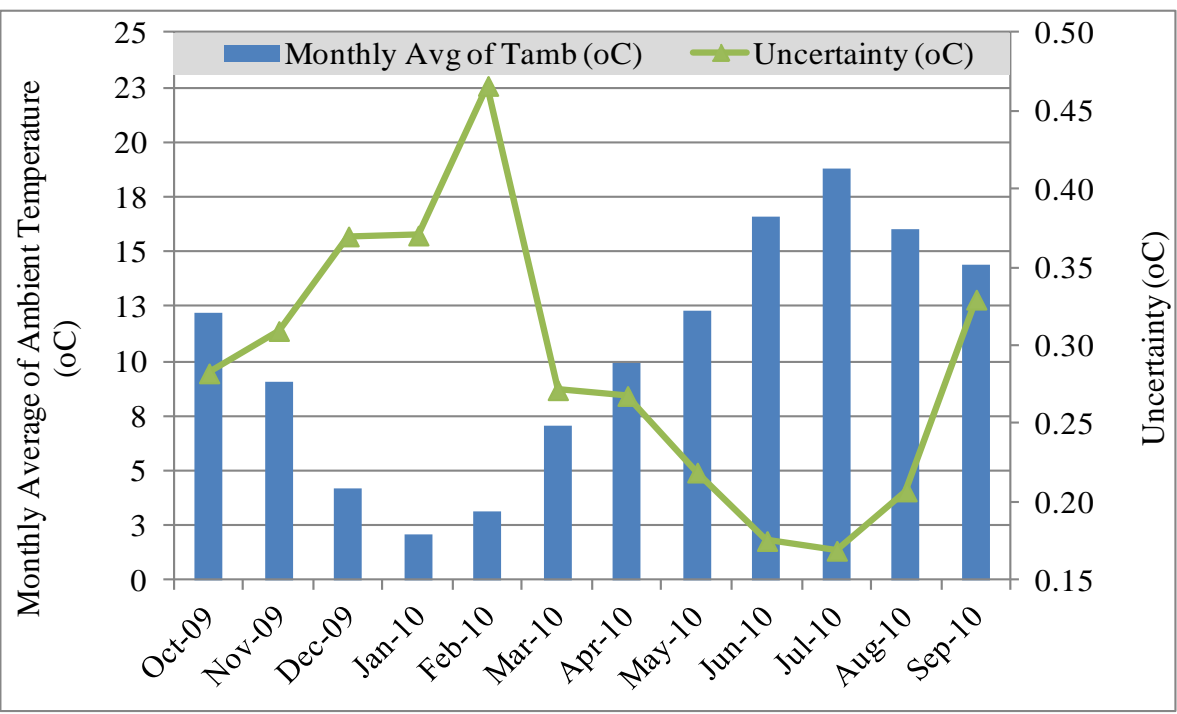


Fig. 10: Monthly energy yield (kW h) and their uncertainties in the UK climate for c-Si module.

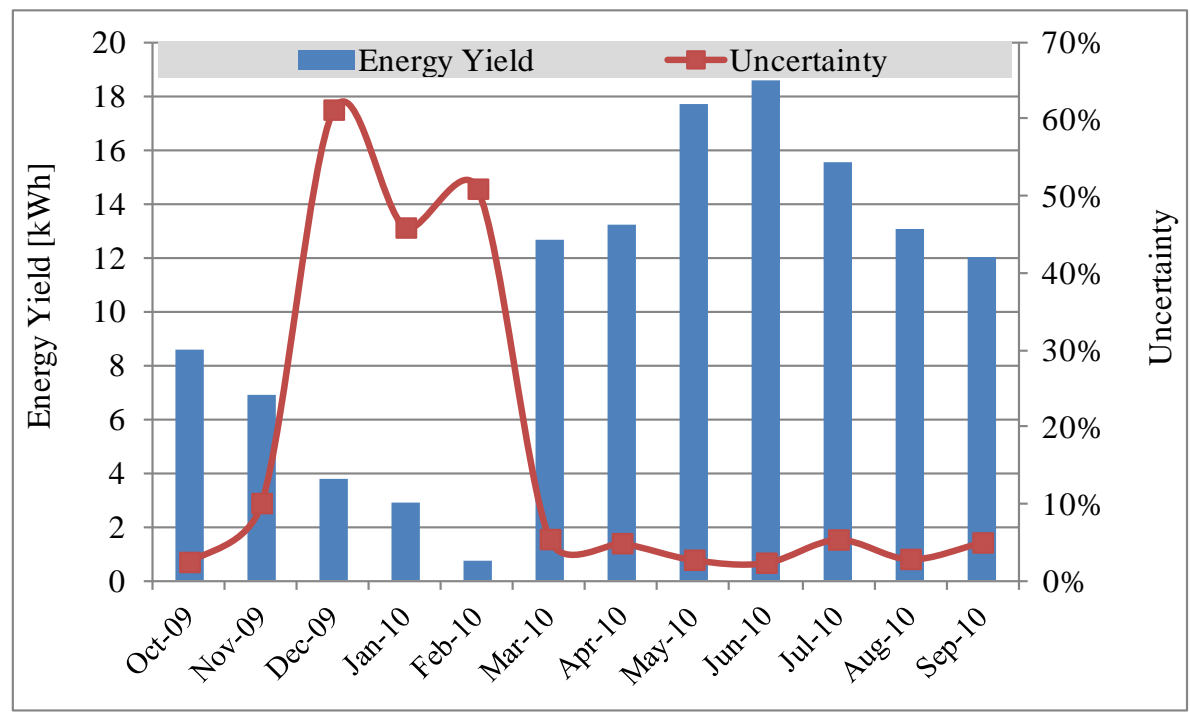

